\title{
Analysis of the Performance of MMC Under Fault Conditions in HVDC-Based Offshore Wind Farms
}

\author{
Ricardo Vidal-Albalate, Hector Beltran, Alejandro Rolán, Enrique Belenguer, Member, IEEE, \\ Rubén Peña, Member, IEEE, and Ramon Blasco-Gimenez, Senior Member, IEEE
}

\begin{abstract}
This paper analyzes the behavior of a modular multilevel converter-high-volatge direct current (MMC-HVDC)-connected offshore wind power plant (WPP) during de faults. For that purpose, detailed models of the dc cable, MMC stations, and transformers have been used in order to obtain reliable results. The influence of the WPP control method in the short-circuit behavior of the HVDC link has also been studied. Results show that the dynamics of the WPP contribution to pole-to-ground faults are slightly slower than those of the wind turbines current control loops. Therefore, the wind turbine front-end converters can be used to reduce the peak and average value of the fault current in such a system. Moreover, it has been found that ferroresonant oscillations can appear in the offshore ac grid when the WPP delivers constant power during faults.
\end{abstract}

Index Terms-Fault analysis, HVDC grid, modular multilevel converter (MMC), offshore wind farm.

\section{INTRODUCTION}

$\mathbf{H}$ IGH-VOLTAGE de (HVDC) links with line-commutated converters (LCCs) have been used for more than 50 years in electric power systems. However, voltage-source converters (VSCs) are being progressively introduced because they enable independent control of active and reactive powers, connection to low short-circuit ratio (SCR) ac grids (or even isolated grids), and facilitate the possibility of creating multiterminal dc grids. As a counterpart, VSCs present higher losses and more complex protection schemes during dc faults than traditional LCCs [1].

Modular multilevel converters (MMCs) are the prefered technology for VSC-HVDC stations [2]. Commonly used half-bridge cells do not have dc-side fault blocking capability, which complicates the development of large multiterminal dc grids [3]. In this regard, new cell topologies have been proposed, such as full-bridge cells or diode-clamp submodules (SMs) [4], [5]. Other converter topologies have also been

Manuscript received December 09, 2014; revised March 26, 2015; accepted July 21,2015 . This work was supported in part by the Spanish Ministry of Economy funds under Grant DPI2014-53245-R, in part by Universitat Jaume I under Grants P1·1B2013-51 and E-2014-24, and in part by CONICYT/FONDAP/15110019 and Fondecyt/1151325.

R. Vidal-Albalate, H. Beltran, A. Rolán, and E. Belenguer are with the Universitat Jaume I, 12071 Castelló de la Plana, Spain (e-mail: rvidal@uji.es; hbeltran@uji.es; rolan@uji.es; efbeleng@uji.es).

R. Peña is with Universidad de Concepción, Concepción [Please provide postal code], Chile (e-mail: rupena@udec.cl).

R. Blasco-Gimenez is with the Universitat Politècnica de València, 46022 València, Spain (e-mail: r.blasco@ieee.org).

Color versions of one or more of the figures in this paper are available online at http://ieeexplore.ieee.org.

Digital Object Identifier 10.1109/TPWRD.2015.2468171 proposed to limit short-circuit currents [6], [7]. However, their greater number of semiconductors increases converter losses. Therefore, half-bridge cells are still widely used due to their higher efficiency.

The influence of capacitor and cable characteristics, number of converter stations, short-circuit location, and ac-grid SCR on short-circuit currents has been studied [8] as well as the influence of different multiterminal topologies (radial, ring, slightly meshed, and highly meshed) [9]. Both [8] and [9] consider twolevel VSC converters with a symmetrical unipolar configuration and dc-side capacitors grounded at their midpoint.

Moreover, several studies analyze dc short circuits when twolevel converters are used [10]-[12]. In [11] and [12], three evolution stages corresponding to the dc-side capacitor discharge, diode freewheeling conduction, and grid-side current feeding an uncontrolled rectifier are proposed to analytically study the response of a two-level converter during short circuits.

The influence of the wind power-plant (WPP) control method has received little attention in published literature, even by those studies that considered MMCs instead of two-level converters [9], [13]. Therefore, previous studies did assume important simplifications regarding the converter, lines, and/or WPP.

The importance of accurate and detailed models can be clearly seen in [14], where the effect of HVDC configuration and grounding system on the system fault response is studied.

In this paper, the influence of the WPP control method on the short-circuit behavior of the HVDC link will be studied. Although pole-to-pole faults would be more severe for the equipment, these are not likely to occur in undersea cables since cable insulation damage in one of the poles would cause, as a first step, a pole-to-ground fault. Hence, only pole-to-ground faults will be considered. Detailed models of the cable, MMC converter stations, and transformers (including saturation) will be used in order to obtain realistic results. It will be shown that the dynamics of the wind farm contribution to pole-to-ground faults are slower than those of the wind turbines current control loops. Therefore, the control strategy used for the wind turbines and the MMCs can be used to reduce the peak and average value of the fault current.

Moreover, it will be shown that sustained ferroresonant oscillations might appear in the offshore grid after an HVDC fault when the wind power plant operates under constant power control and the offshore MMC acts as a grid-former converter.

This paper is organized as follows. Section II introduces a brief description of the system under study, including the description of the MMC model. An analytical study and simplified expressions to determine the system dynamics are presented in 


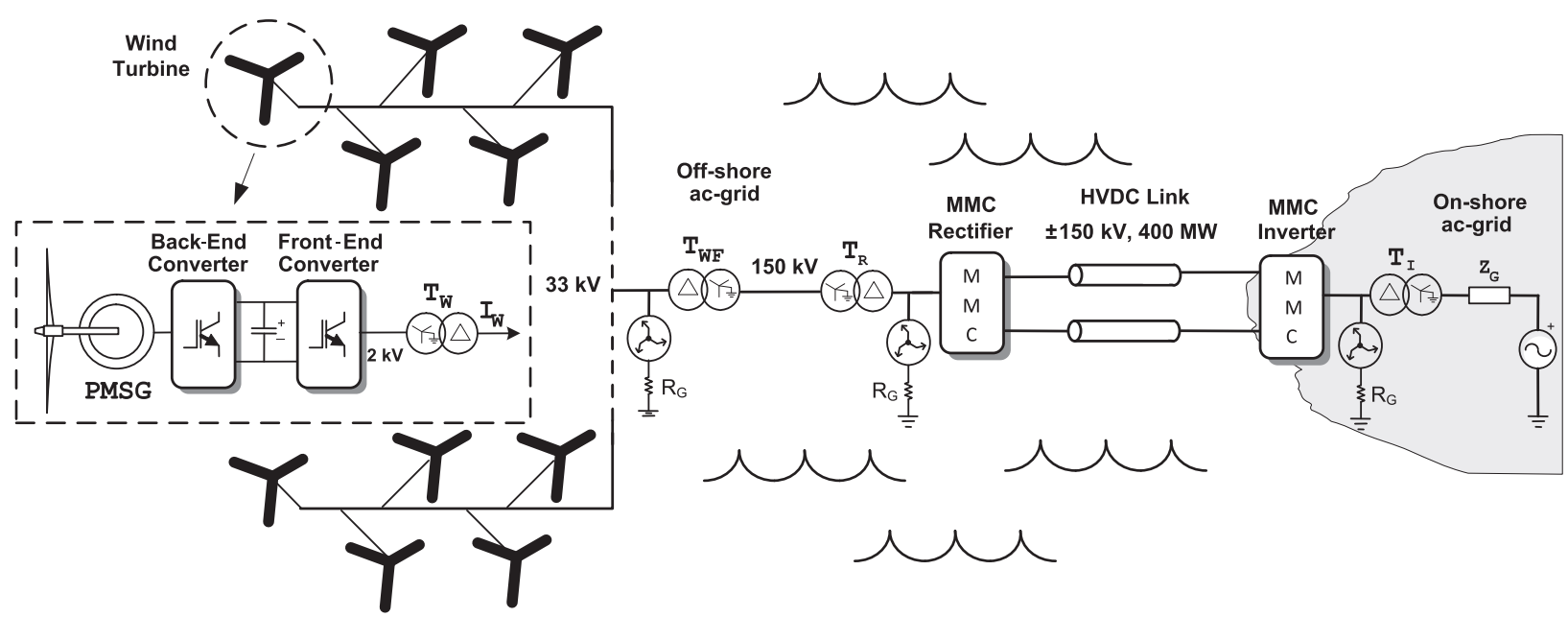

Fig. 1. PMSG-based offshore wind farm with an HVDC connection.

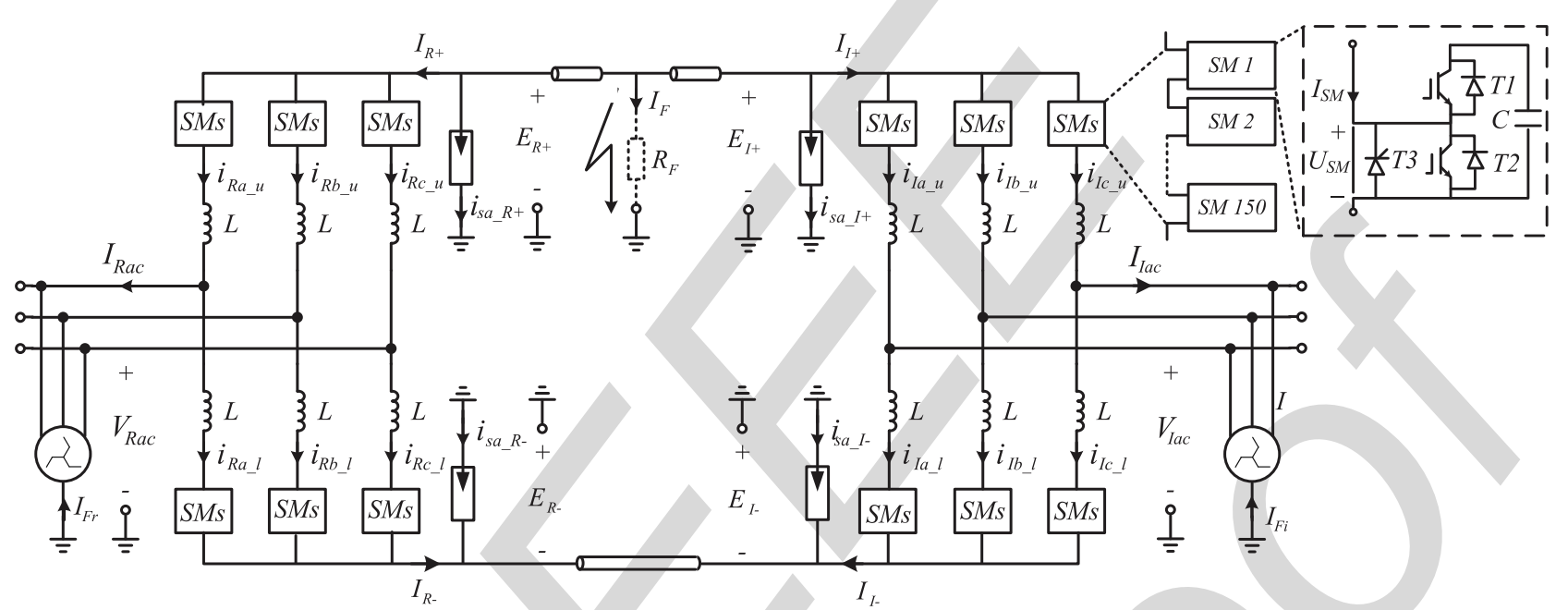

Fig. 2. MMC-HVDC link.

Section III. Section IV is devoted to presenting simulations results under several scenarios. Finally, a discussion is presented in Section V and some conclusions are stated in Section VI.

\section{System Modeling}

The system under study (Fig. 1) consists of a permanent-magnet synchronous generator (PMSG)-based 400-MW offshore WPP connected to the onhore grid through a $\pm 150-\mathrm{kV}$ HVDC link with a symmetrical monopolar configuration. The system uses half-bridge MMC stations with zig-zag transformers for their earth connection. Low-impedance grounding has been considered in order to provide a reasonable limit to HVDC cable overvoltages during pole-to-ground faults. The proposed ground impedance represents a tradeoff between cable overvoltage (and surge arrester rating) and maximum fault current magnitude [15], [16].

The onshore converter controls the HVDC voltage, whereas the offshore converter acts as a grid-forming converter for the offshore ac grid, setting its frequency and voltage. The wind turbines are controlled to track their optimal power reference. The wind turbine back-end converters regulate the back-to-back converters' dc-link voltage by controlling the generator currents via a field-oriented control technique [17]. This description corresponds to the typical exploitation of offshore WPPs although other configurations are possible (e.g., wind turbines working as grid-forming units [18]).

A detailed model of the WPP has been built in PSCAD. Two 151-level MMC stations have been simulated (see Fig. 2) by using a simplified model that accurately reproduces the dynamic behavior during transients [19]. As dc currents and voltages might appear on the MMC ac terminals during dc-side short circuits, magnetic saturation has been considered for the power transformers. Saturation is represented by means of a compensating current source across the winding closest to the core [20]. For accurate cable simulation, a frequency-dependent phase model that takes into account the cable physical properties is used [21]. A complete list of parameters for system analysis and simulation is in the Appendix.

\section{A. MMC Simplified Model}

A detailed diagram of the MMC converter stations and the HVDC cable under study are shown in Fig. 2. The converter stations consist of a three-phase MMC with 150 half-bridge cells per arm. In addition, all of the SMs include a thyristor (T3) 


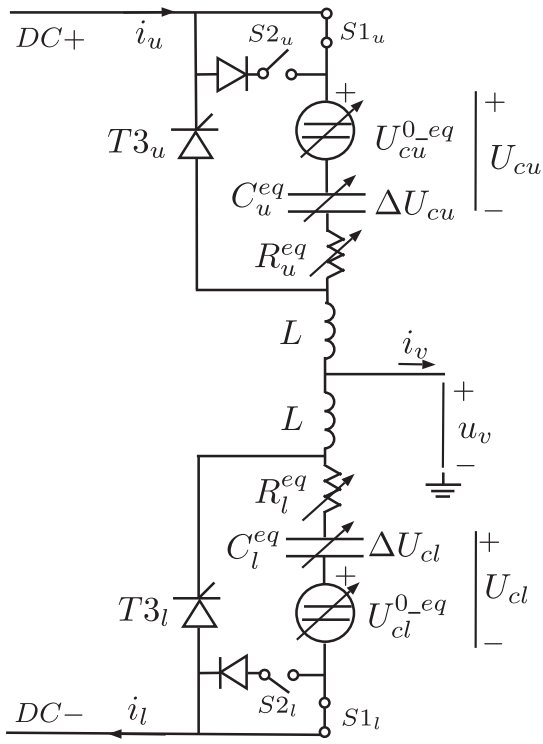

Fig. 3. Equivalent circuit of one MMC converter phase.

which is fired in the event of a de fault to avoid damaging overcurrents flowing through the SM diodes.

The high number of components considered would lead to extremely large simulation times in electromagnetic transient programs. In this paper, a simplified but accurate and efficient model is used to study the behavior of the MMCs during dc faults [13], [19], [22]. The simplified model used has been thoroughly verified against full models with a reduced number of SMs both for steady state and fault operation [19].

One phase of the simplified model, which is based on a Thevenin's equivalent circuit of each arm, is shown in Fig. 3. All cells in each arm are replaced by a variable voltage source, a variable capacitor, and a variable resistor regardless of the number of levels. When there is a change in the number of cells to be inserted in the arm, the equivalent voltage, capacitance, and resistance values are updated.

In order to achieve consistent behavior when the protections are triggered, the protecting thyristors $T 3_{u, l}$ are also included in the simplified model. In addition, during the fault, the ideal switches $S 1_{u, l}$ are opened and the ideal switches $S 2_{u, l}$ are closed to accurately consider the MMC behavior during faults. Further details about the MMC simulation technique and its validation can be found in [19].

A standard voltage-balancing algorithm is used for the MMC [23]. A control algorithm to reduce the circulating current among the legs has also been used [24] in both converter stations.

\section{SySTEM ANALYSIS}

This section is devoted to the analysis of the currents flowing through the MMC when a pole-to-ground dc fault is experienced (Fig. 2). To derive the analytical expressions, a $\pi$-equivalent model for the cable is used, with the corresponding characteristic parameters [21].

It should be highlighted that the offshore MMC rectifier is directly fed by the WPP, which controls the active power delivered

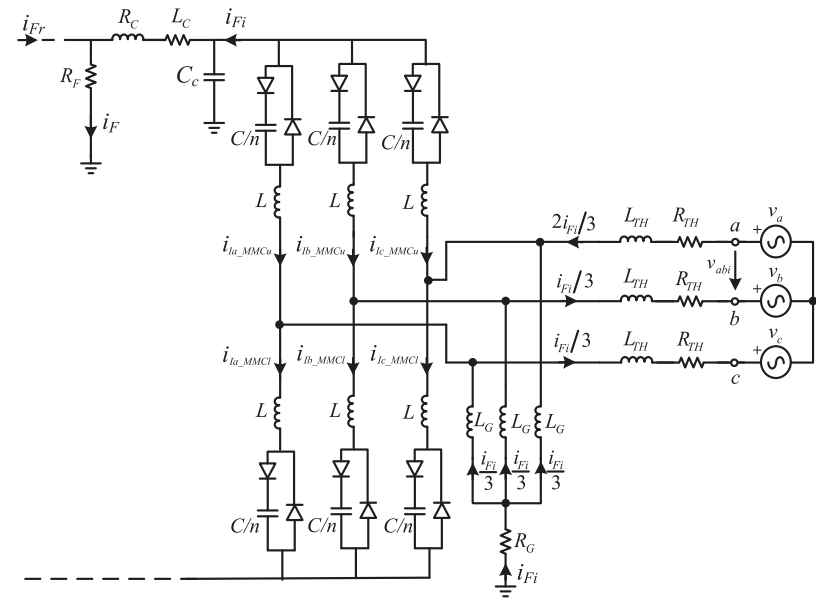

Fig. 4. Equivalent MMC circuit with protection thyristors triggered.

to the HVDC link, whereas the MMC inverter is connected to the onshore ac grid, which can be represented by its Thevenin equivalent. Hence, the fault behavior of each converter is different.

Therefore, the fault current analysis will be first carried out for a scenario where both converter stations are connected to the ac grids. Then, the study will be extended to incorporate the constant power performance of the WPP during the fault.

\section{A. Short-Circuit Behavior When Connecting Two AC Grids}

At the onset of a pole-to-ground fault, the converter control tries to keep its normal operation until the protections are fired. After a few milliseconds, the protecting thyristors are triggered (either by overcurrent or by overvoltage trips).

Once the protection thyristors are fired, the three upper arms of the MMC behave like a three-phase half-wave rectifier, as shown in Fig. 4.

The total fault current $\left(i_{F}\right)$ will be the addition of the fault currents fed from each converter and the cable discharge current

$$
i_{F}(t)=i_{F i}(t)+i_{F r}(t)+i_{F c}(t)
$$

where $i_{F i}, i_{F r}$ are the fault currents from the inverter and rectifier converters and $i_{F c}$ is the cable discharge current. These three components will be calculated as follows.

From Fig. 4, the following expression for the onshore inverter fault current is obtained:

$$
\begin{aligned}
v_{a b i}= & \left(R_{c}+R_{\mathrm{TH}}+R_{G}\right) i_{F_{i}}+R_{F}\left(i_{F_{r}}+i_{F_{i}}+i_{F c}\right) \\
& +\left(\frac{2}{3} L_{\mathrm{TH}}+L+L_{c}+\frac{1}{3} L_{G}+\frac{1}{3} L_{\mathrm{TH}}\right) \frac{d i_{F_{i}}}{d t} \\
v_{a b i}= & R_{T_{i}} i_{F_{i}}+L_{T_{i}} \frac{d i_{F_{i}}}{d t}+R_{F}\left(i_{F_{r}}+i_{F_{i}}+i_{F c}\right)
\end{aligned}
$$

where $R_{T_{i}}=R_{c}+R_{T H}+R_{G}$ is the equivalent total resistance and $L_{T_{i}}=L_{\mathrm{TH}}+L+L_{c}+(1 / 3) L_{G}$ is the equivalent total inductance of the circuit in Fig. 4.

Similarly, the expression of the offshore fault current can be obtained

$$
v_{\mathrm{abr}}=R_{T_{r}} i_{F_{r}}+L_{T_{r}} \frac{d i_{F_{r}}}{d t}+R_{F}\left(i_{F_{r}}+i_{F_{i}}+i_{F c}\right)
$$




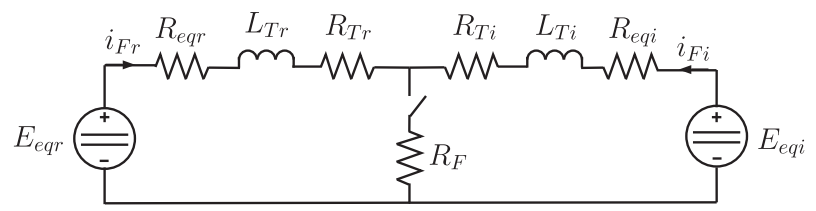

Fig. 5. Equivalent circuit for the transient response.

where $R_{T_{r}}=R_{c}+R_{\mathrm{TH}}+R_{G}$ is the equivalent total resistance and $L_{T_{r}}=L_{\mathrm{TH}}+L+L_{c}+(1 / 3) L_{G}$ is the equivalent total inductance of the offshore rectifier station.

To obtain steady-state fault currents, the overlap angle has to be considered. For a half-wave rectifier bridge

$$
\begin{aligned}
& R_{e q}=\frac{3 \omega\left(L_{\mathrm{TH}}+L\right)}{2 \pi} \\
& E_{\text {eq }}=\frac{3}{\pi \sqrt{2}} V_{a b}
\end{aligned}
$$

where $R_{\mathrm{eq}}$ is an equivalent resistance in series with $R_{T}$, and $E_{\text {eq }}$ is the equivalent dc voltage at the converter terminals. Fig. 5 shows the equivalent circuit for fault current calculation, considering overlap angles for both converters. Note that $i_{F c}$ does not contribute to the steady-state fault current.

Therefore, the steady-state fault currents through each converter $I_{F i \infty}$ and $I_{F r \infty}$ are calculated as follows:

$$
\begin{aligned}
& {\left[\begin{array}{c}
I_{F i \infty} \\
I_{F r \infty}
\end{array}\right]} \\
& \quad=\left[\begin{array}{cc}
R_{T i}+R_{F}+R_{\text {eqi }} & R_{F} \\
R_{F} & R_{T r}+R_{F}+R_{\text {eqr }}
\end{array}\right]^{-1}\left[\begin{array}{c}
E_{\text {eqi }} \\
E_{\text {eqr }}
\end{array}\right]
\end{aligned}
$$

where $R_{\text {eqi }}$ and $R_{\text {eqr }}$ are the equivalent resistances for the onshore and offshore converter, respectively. Analogously, $E_{\text {eqi }}$ and $E_{\text {eqr }}$ are the equivalent voltage source values for the onshore and offshore converter, respectively.

The expressions for the transient evolution of the onshore $\left(i_{F i}(t)\right)$ and offshore $\left(i_{F r}(t)\right)$ fault currents can be obtained by solving the following system of equations and applying the inverse Laplace transform (Fig. 5):

$$
\begin{array}{r}
{\left[\begin{array}{cc}
R_{T i}+R_{F}+R_{e q i}+L_{T i} s & R_{F} \\
R_{F} & R_{T r}+R_{F}+R_{\text {eqr }}+L_{T r} s
\end{array}\right]\left[\begin{array}{c}
i_{F i} \\
i_{F r}
\end{array}\right]} \\
=\left[\begin{array}{c}
E_{\text {eqi }} \\
E_{\text {eqr }}
\end{array}\right] .
\end{array}
$$

At this stage, the contribution of the cable discharge to the total fault current should be considered as

$$
i_{F c}(t)=\frac{E_{0}}{\omega_{c} L_{c}} e^{-\delta t} \sin \left(\omega_{c} t\right)
$$

where $E_{0}$ is the pole voltage at the fault onset, and

$$
\begin{aligned}
\delta & =\frac{R_{c}+R_{F}}{2 L_{c}} \\
\omega_{c}^{2} & =\frac{1}{L_{c} C_{c}}-\left(\frac{R_{c}+R_{F}}{2 L_{c}}\right)^{2}
\end{aligned}
$$

where $R_{c}, L_{c}$, and $C_{c}$ are the cable resistance, inductance, and capacitance, respectively. For cables of the considered rating and length, (9) leads to an underdamped response much faster than the station fault dynamics in (8). Therefore, it is sensible

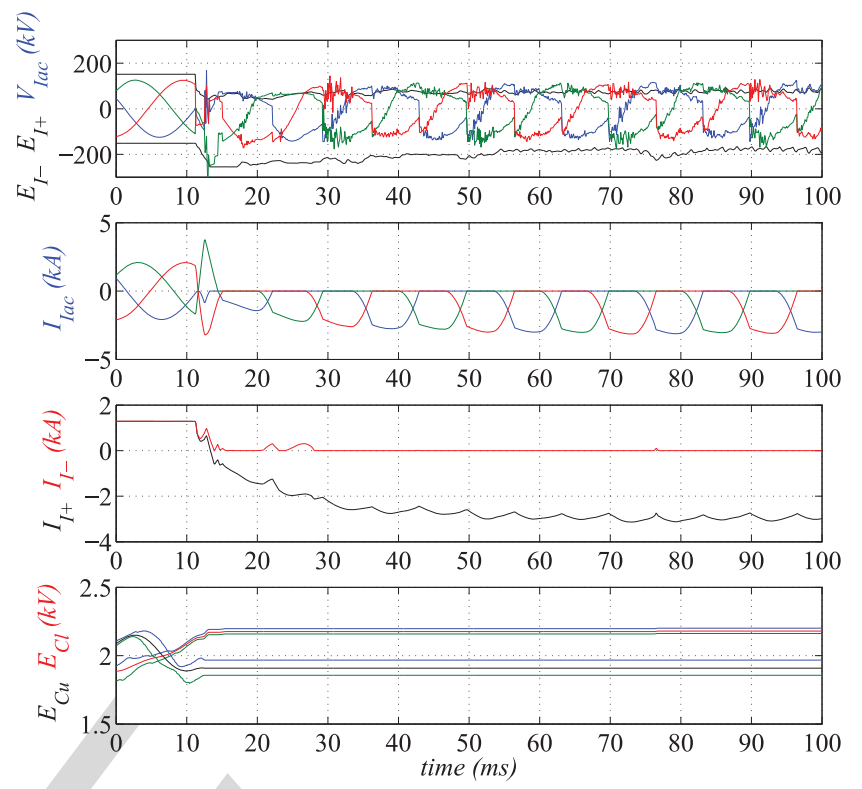

Fig. 6. Onshore MMC station behavior when thyristor protections trigger 1.5 $\mathrm{ms}$ after the fault.
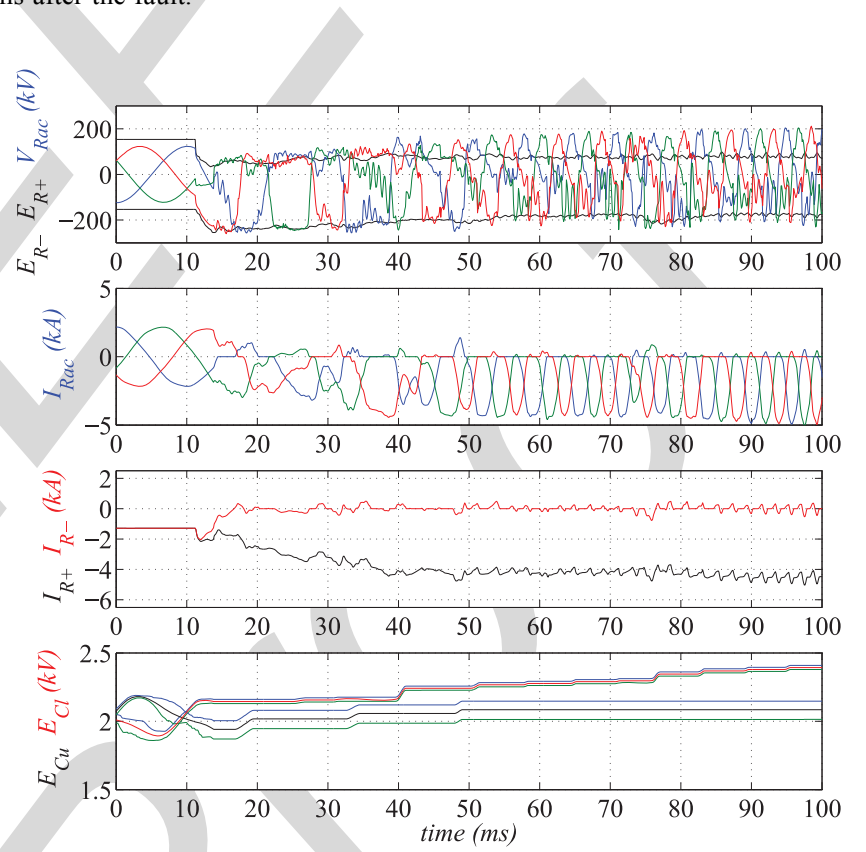

Fig. 7. Offshore MMC station behavior when thyristor protections trigger $3 \mathrm{~ms}$ after the fault.

to assume that $i_{F}(t)=i_{F i}(t)+i_{F r}(t)$ for values of $t$ above a few milliseconds after the fault. This simplification has been verified by means of a detailed simulation (Fig. 8).

The negative pole voltage at each converter station will be

$$
E_{R-}(t)=-2 E_{0}+R_{F} i_{F}(t)+R_{c r} i_{F r}(t)
$$

where $R_{c r}$ is the cable resistance from the fault point to the rectifier station. Similarly

$$
E_{I-}(t)=-2 E_{0}+R_{F} i_{F}(t)+R_{c i} i_{F i}(t)
$$

where $R_{c i}$ is the cable resistance from the fault point to the inverter station. 


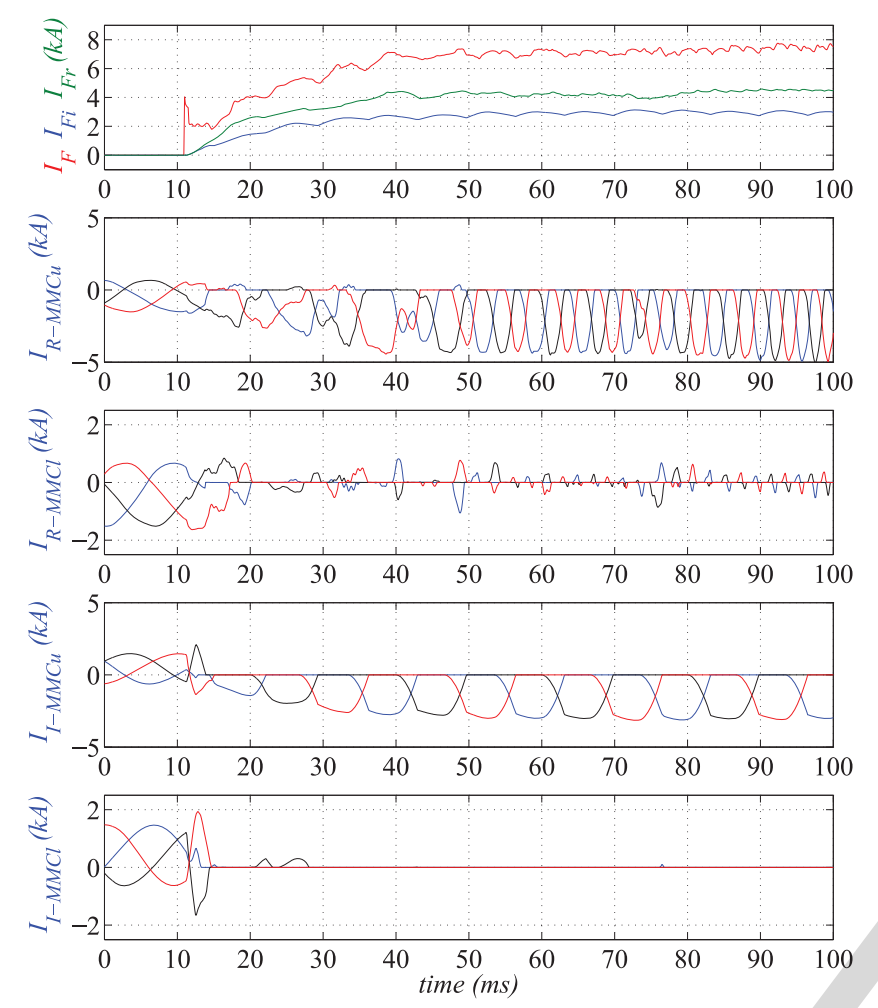

Fig. 8. Fault and MMC branch currents during the fault when thyristors are triggered.

\section{B. Influence of the WPP on the Short-Circuit Behavior}

If one of the converter stations is connected to a WPP, the overall response will be influenced by the WPP. Taking into account that the wind turbines are controlled to track their optimal power reference, the WPP can be considered as a constant power current source during the duration of the fault and, therefore, the offshore current fault is determined by the operating point of the WPP just before the fault onset. The previous analysis is still valid but consider in this case that the fault power from the offshore converter has to equalize the power generated by the WPP. Taking this into account, (7) becomes

$$
\left.\begin{array}{rl}
\left(R_{T i}+R_{F}+R_{\text {eqi }}\right) I_{F i \infty}+R_{F} I_{F r \infty} & =E_{\text {eqi }} \\
R_{F} I_{F i \infty}+\left(R_{T r}+R_{F}+R_{\text {eqr }}\right) I_{F r \infty} & =E_{\text {eqr }} \\
\left(E_{\text {eqr }}-R_{\text {eqr }} I_{F r \infty}\right) I_{F r \infty} & =P_{\mathrm{WPP}}
\end{array}\right\}
$$

where $P_{\mathrm{WPP}}$ is the power generated by the WPP before the fault onset.

Therefore, the values of $I_{F r \infty}, I_{F i \infty}$, and $E_{\text {eqr }}$ are obtained from (14), and the dynamic response of the fault currents can be calculated according to (8).

The presented analysis can be used to design adequate values of ground impedance, transformer, and MMC converter inductance in order to provide an adequate tradeoff between maximum fault current, fault current dynamics, and maximum pole overvoltage.

Clearly, the aforementioned fault current study can easily be extended to a multiterminal scenario.

\section{CASE STUdies}

A pole-to-ground fault is applied at the midpoint of the positive pole of the HVDC link at $\mathrm{t}=11 \mathrm{~ms}$, with a fault resistance of $10 \Omega$ when the offshore wind farm is delivering its rated power $(400 \mathrm{MW})$.

\section{A. Case A) Operation With Activated MMC Protections}

In this case study, thyristor protections are activated after fault detection. Inverter protections are triggered when the branch current reaches $1.4 \mathrm{pu}(2.1 \mathrm{kA})$, which occurs $1.5 \mathrm{~ms}$ after the fault onset. The 1.4-p.u. current trigger point is selected in such a value to prevent the current from flowing through the insulated-gate bipolar transistor (IGBT) diodes to rise above their specified peak forward current.

Current triggering of the offshore rectifier station would lead to much longer delay, as offshore arm currents take more than $11 \mathrm{~ms}$ to reach 1.4 p.u. At this stage, the offshore rectifier station would trigger negative pole overvoltage, as it reaches 1.7 p.u. in about $3 \mathrm{~ms}$. Again, a 1.7-p.u. overvoltage setpoint represents an acceptable tradeoff to avoid cable overvoltage without requiring increased surge arrester rating.

Figs. 6 and 7 show the behavior of the onshore and offshore converters when the converter thyristors are triggered and the wind farm is delivering its rated power. Onshore ac-grid currents correspond to the well-known currents of a half-bridge rectifier.

The offshore MMC ac terminal currents also exhibit the behavior of a half-bridge uncontrolled rectifier, despite no gridforming converter being operational in the offshore ac grid. The offshore grid ac voltage oscillations are caused by resonance between the offshore ac grid transformers' inductance and capacitors and sustained by the wind farm active power generation. The oscillation frequency is about $160 \mathrm{~Hz}$ and is a function of the transformer saturation characteristics. In practice, the oscillations would cause the wind turbines to trip on overfrequency and/or overvoltage. However, this effect is relevant, as the wind farm is capable of injecting active power to the offshore ac grid even when the MMC substation protections have been triggered. At little or no load, the oscillation frequency is close to the natural frequency of the offshore ac grid. This is to be expected, as, at this frequency, the total reactive power on the offshore ac grid is zero. Since the reactive power absorbed by the rectifier is power dependent, the oscillation frequency will change depending on the active power level, in order to maintain the reactive power balance.

The high-frequency oscillations might lead to overvoltages (albeit limited by transformer saturation). In such situation, diodes T1 (see Fig. 2) can be forward-biased if the dc-pole to ac-phase voltage is higher than the total capacitor voltage in one arm. In that case, the current flows through the SM capacitors and their voltages increase. This fact can be appreciated by the positive ac current components seen in Fig. 7 from $t=20 \mathrm{~ms}$ onwards. However, this effect is not experienced in the onshore converter since it is connected to the transmission ac grid that fixes the ac voltage.

The protection mechanism drives the negative pole current to zero in both converter stations while keeping the cell capacitor voltages within reasonable limits. 


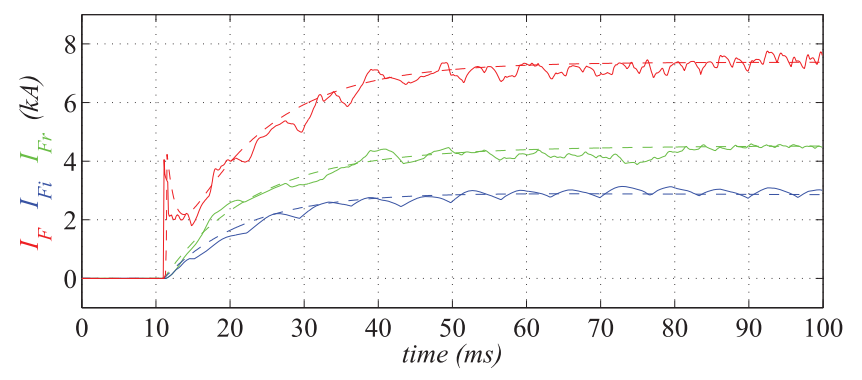

Fig. 9. Comparison of the estimated (dashed lines) and simulated fault currents (solid lines).

Fig. 8 shows the current through the fault resistor $\left(I_{F}\right)$ and through the inverter and rectifier stations' zig-zag transformers $\left(I_{F i}\right.$ and $I_{F r}$ ) as well as the top and bottom branch currents of both converters. Fault currents settle to their steady-state value in about $40 \mathrm{~ms}$ after the fault.

At the beginning of the fault, the cable capacitance discharges through the fault resistance. At this stage, there is no fault current flowing through the zig-zag transformers. After $3 \mathrm{~ms}$, the total fault current is the addition of the rectifier and inverter zig-zag transformer currents.

The fault current $I_{F}$ shows an initial peak of around $4 \mathrm{kA}$ due to the discharge of the cable capacitance through the fault resistance. The cable capacitance discharge transient lasts around 3 ms. The fault current $I_{F}$ reaches $5 \mathrm{kA}$ in about $15 \mathrm{~ms}$ and a peak of $7.5 \mathrm{kA}$ in $40 \mathrm{~ms}$ after the fault onset.

Currents through the bottom arms of both converters are zero once the protections are triggered and all of the ac currents flow through the top arms of the converters.

Fig. 9 shows the comparison of the estimated fault currents values obtained from the analytical study and the simulated fault currents values. For the parameters used (see the Appendix), when the WPP is delivering its rated power, calculated steadystate fault currents of $2.73 \mathrm{kA}$ and $4.61 \mathrm{kA}$ are obtained for the onshore and offshore converters, respectively. The settling time of the transient response is about $40 \mathrm{~ms}$. These values are in an excellent agreement with the simulation results.

\section{B. Case B) Wind Power-Plant Power Reduction During Faults}

The results in the previous section point out that a reduction on peak fault current is possible if the WPP can reduce its generated power in less than $40 \mathrm{~ms}$ after the fault onset. Wind turbines should be remotely triggered by the offshore converter station, as voltages and currents on wind turbine terminals do not significantly depart from their rated values within $40 \mathrm{~ms}$.

Figs. 10-12 show the behavior of the onshore and offshore converter stations when a power reduction command is issued to the WPP. It is assumed that the communication delay between the offshore converter station and the wind turbines is $5 \mathrm{~ms}$. Hence, power reduction is activated $8 \mathrm{~ms}$ after the onset of the fault.

When a $5-\mathrm{ms}$ communication delay is considered, the maximum rectifier and total fault currents decrease by $33 \%$ and $31 \%$, respectively. For a 20 -ms delay, the values are $14 \%$ and $15 \%$,
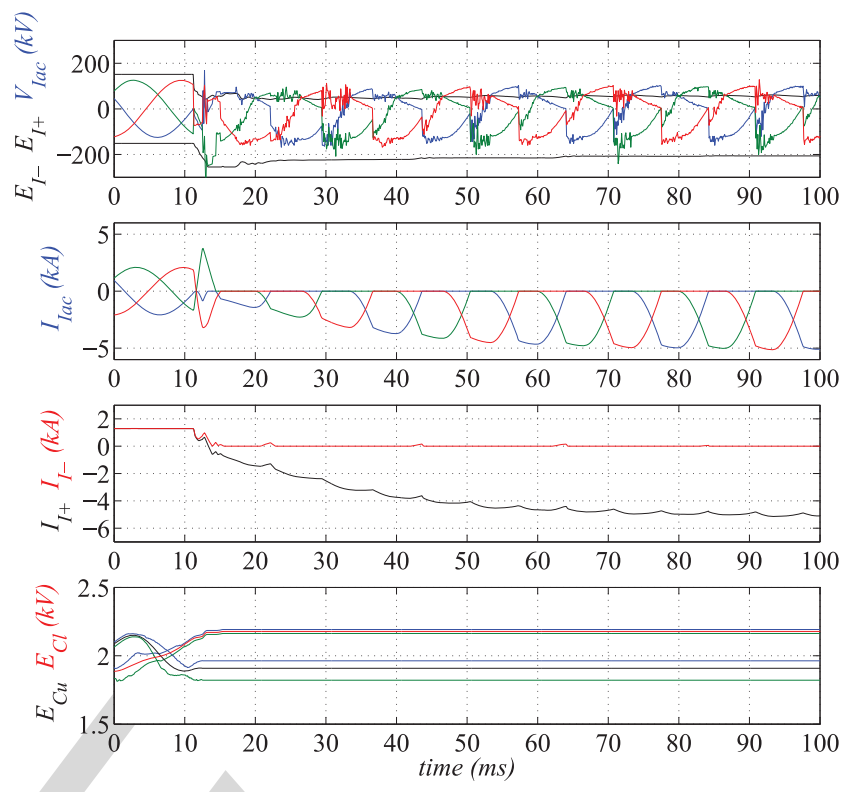

Fig. 10. Onshore MMC station behavior when thyristors are triggered, and WPP delivered power is reduced.

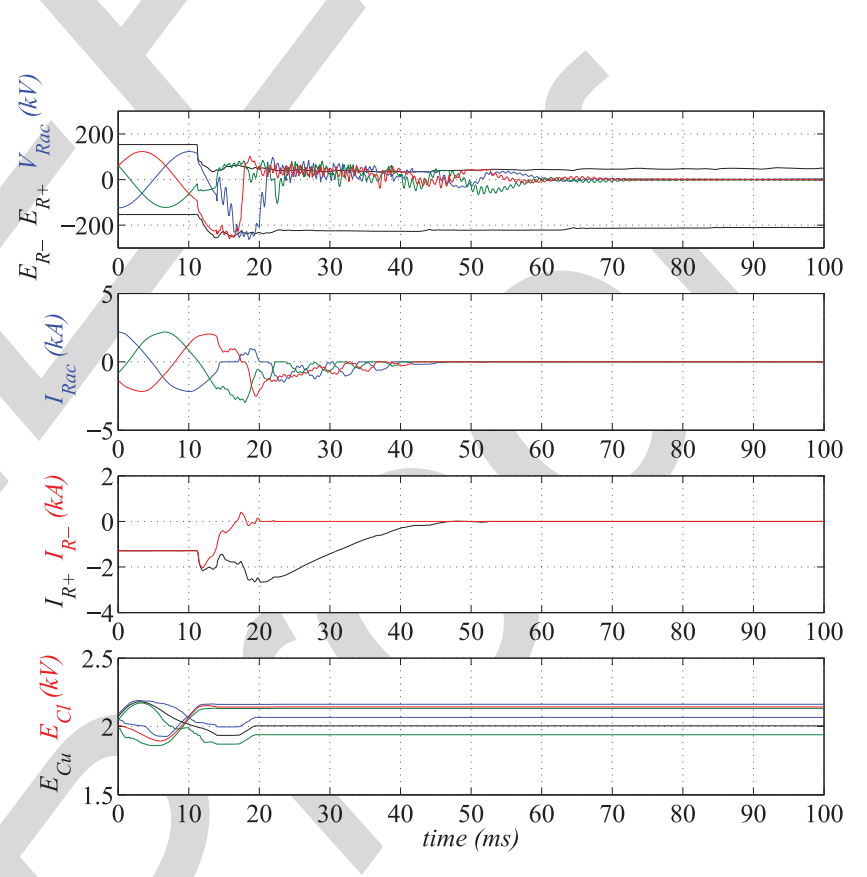

Fig. 11. Offshore MMC station behavior when thyristors are triggered, and WPP delivered power is reduced.

respectively. In all cases, the steady-state rectifier current is reduced to zero, and the total fault current settles to $5.2 \mathrm{kA}$, which corresponds to a reduction of $31 \%$, per (14).

Once the power reduction command is received, the offshore converter currents (Fig. 11) are reduced to zero in about $20 \mathrm{~ms}$ following the wind turbine current dynamics. The wind farm power reduction causes the ac-grid oscillations to die out in about $22 \mathrm{~ms}$. In steady state, the currents through both converter poles is zero, while cell capacitor voltages are kept within reasonable limits.

The behavior of the onshore converter (Fig. 10) is very similar to that of case a) shown in Fig. 6, with the exception that the 


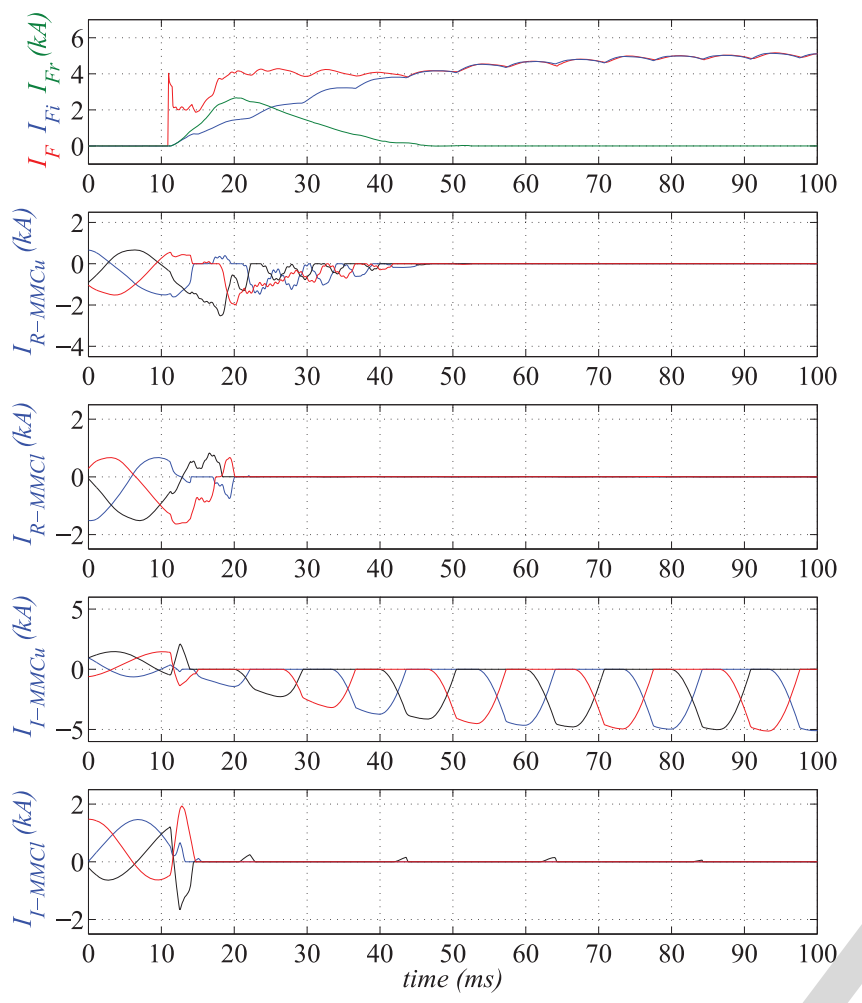

Fig. 12. Fault and MMC branch currents when thyristors are triggered, and WPP delivered power is reduced.

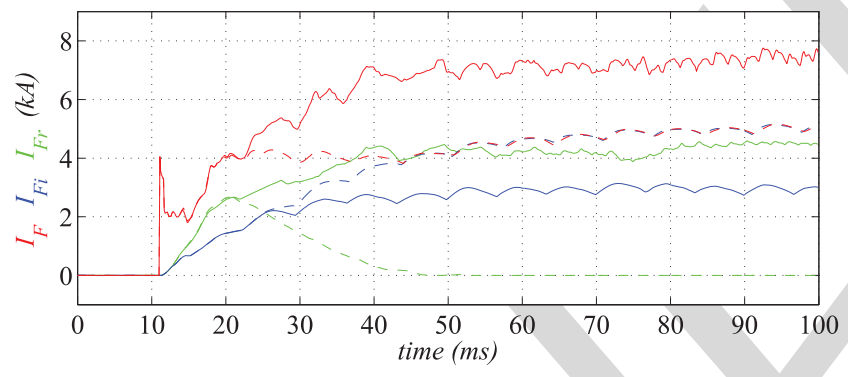

Fig. 13. Comparison of the fault currents for cases a) (solid lines) and b) (dashed lines).

positive pole current $\left(I_{I+}\right)$ is now substantially larger. The reduction of the overall fault current means that the voltage drop on the fault resistance $\left(R_{F}\right)$ is smaller and, hence, the inverter fault current increases. However, overall fault current decreases with respect to case b).

Fault currents and converter currents during the fault are shown in Fig. 12, where the reduced contribution of the offshore converter to overall fault current is clearly seen.

Fig. 13 shows the fault currents for both cases, that is, with and without wind farm power reduction. It becomes relevant that whereas some kind of additional protection is required for the onshore converter, overcurrents on the offshore converter can be entirely avoided by WPP power reduction.

\section{Discussion}

The proposed technique for offshore converter maximum fault current reduction can only be accomplished if communication between the converter station and the WPP is sufficiently fast and, moreover, if the proposed strategy does not adversely affect the wind turbines themselves.

Communication delays of $5 \mathrm{~ms}$ and below are reasonable with dedicated fiber optics for protection coordination. Delays of 20 $\mathrm{ms}$ are also well within technological reach of current real-time industrial communication networks (e.g., EtherCAT over fiber optics).

Large active power transients produced by the current limitation strategy might lead to unacceptable mechanical stress. However, certified wind turbines should withstand mechanical stresses caused by grid disconnection or by ac grid faults [25], provided that such events are not excessively frequent. Clearly, HVDC short circuits are nonfrequent events and, hence, mechanical elements of certified wind turbines can withstand them without significant degradation.

In addition, a detailed NREL-FAST - PSCAD co-simulation study has been carried out to evaluate the mechanical stress increase due to the proposed current mitigation strategy. The study assumes $15-\mathrm{m} / \mathrm{s}$ wind, with $10 \%$ turbulence and a wind turbine back-to-back converter with a dynamic braking resistor that can absorb rated power during $1 \mathrm{~s}$. Under these conditions, gearbox torsional moment, blade root, and tower base moments do not significantly increase, provided that the mechanical torque can be ramped down in about $1 \mathrm{~s}$ using dynamic braking.

Therefore, the proposed current limitation strategy does not lead to excessive mechanical loads nor reduces the operational life of the wind turbine due to increased fatigue.

\section{CONCLUSIONS}

This paper presents a study on the behavior of a symmetrical monopolar VSC-HVDC link connecting a wind power plant during cable faults. Particular attention has been paid to the use of a detailed and accurate model of the system, including 151-level MMC stations as well as detailed cable and transformer models (including saturation).

The study points out the different behavior of the onshore and offshore converter stations during faults, when the offshore MMC station is controlled as a grid former converter and the WPP delivers optimal active power.

Their different behaviors can be observed with and without protecting thyristors being activated. In both cases, high-frequency oscillations might appear in the offshore ac grid due to the saturation characteristic of the transformers and the fact that the WPP is under constant power control. This behavior does not appear when transformer saturation is not considered.

It has been found that the time constant of the WPP contribution to the fault current is slow enough to allow for WPP power reduction after the fault. This strategy keeps the off-shore MMC currents below maximum levels during the complete transient, and it leads to zero pole currents on the off-shore station. Moreover, ferro-resonant oscillations disappear as no active power is feeding the resonance anymore.

When using WPP power reduction after the fault, onshore converter fault currents increase slightly, although overall fault currents are reduced.

Finally, it has been clearly shown that wind power plants operating to deliver reference optimal power cannot be considered as voltage sources for accurate HVDC fault studies. 


\section{APPENDIX \\ SYSTEM PARAMETERS}

Offshore AC Grid:

- 33-kV grid: $33 \mathrm{kV}$ (L-L rms), $500 \mathrm{MVA}, 50 \mathrm{~Hz}$

Cable parameters: $C=0.38 \mu \mathrm{F} / \mathrm{km}, L=0.031 \mathrm{mH} / \mathrm{km}$, length $=20 \mathrm{~km}$.

- 150-kV grid: $150 \mathrm{kV}$ (L-L rms), $500 \mathrm{MVA}, 50 \mathrm{~Hz}$ Cable parameters: $C=0.27 \mu \mathrm{F} / \mathrm{km}, L=0.54 \mathrm{mH} / \mathrm{km}$, length $=4 \mathrm{~km}$.

- Wind Turbine Transformer $\mathrm{T}_{W}: 400 \mathrm{MW}, 2 / 33 \mathrm{kV}$ (L-L rms), $L_{W}=0.06$ p.u., $\mathrm{R}_{W}=0.005$ p.u.

- Step-Up Transformer $\mathrm{T}_{W F}: 500 \mathrm{MVA}, 33 / 150 \mathrm{kV}$ (L-L rms), $\mathrm{L}_{W F}=0.1$ p.u., $\mathrm{R}_{W F}=0.01$ p.u.

- Zig-Zag Transformer $\mathrm{T}_{z 33}$ [16]: 5 MVA, $50 \mathrm{~Hz}, 19.05 /$ $19.05 \mathrm{kV}$ (L-L rms), $L_{z 33}=0.16$ p.u.

- Reactive Power Compensation Capacitors: $150 \mu \mathrm{F}$. HVDC Link: Base Values: $\pm 150 \mathrm{kV}, 400 \mathrm{MW}, 100 \mathrm{~km}$.

- Cable characteristics: [26]

\begin{tabular}{llcccc} 
Layer & Material & Radius $(\mathrm{mm})$ & $\rho(\mathrm{n} \Omega \mathrm{m})$ & $\epsilon_{R}$ & $\mu$ \\
\hline Conductor & Copper & 18.2 & 17.6 & - & 1 \\
Insulation & LXPE & 33.2 & - & 2.5 & 1 \\
Sheald & Lead & 36.2 & 220 & - & 1 \\
& alloy & & & & \\
Inner jacket & PE & 38.8 & - & 2.3 & 10 \\
Armour & Galvanic & 43.8 & 180 & - & 1 \\
& steel & & & & \\
Outer cover & PP & 48 & - & 2.2 & 1.
\end{tabular}

- Offshore Converter Transformer $\mathrm{T}_{R}: 500 \mathrm{MVA}, 50 \mathrm{~Hz}$, $150 / 150 \mathrm{kV}$ (L-L rms), $L=0.10 \mathrm{pu}, R=0.01$ p.u.

- Onshore Converter Transformer $\mathrm{T}_{I}: 500 \mathrm{MVA}, 50 \mathrm{~Hz}$, $150 / 400 \mathrm{kV}$ (L-L rms), $L=0.10$ p.u., $R=0.01$ p.u.

- MMC Zig-zag Transformers $\mathrm{T}_{z}: 5 \mathrm{MVA}, 50 \mathrm{~Hz}, 86.60 /$ $86.60 \mathrm{kV}$ (L-L rms), $L_{z}=0.16$ p.u.

- MMCs: 435 MVA ( $P=400 \mathrm{MW}, Q= \pm 170 \mathrm{MVAr}), 151$ levels, $L=0.15$ p.u., $R=0.0025$ p.u., $C=9.67 \mathrm{mF}$. Onshore AC Grid: Base Values: 500 MVA, 400 kV (L-L rms), $50 \mathrm{~Hz}$.

- Line inductance and resistance: $L_{G}=0.09848$ p.u., $R_{G}=$ 0.017365 p.u.

- Short-circuit ratio: $\mathrm{SCR}=10$

Transformers Saturation Model:

- Air-core reactance: 0.20 p.u.

- Knee voltage: 1.25 p.u.

\section{REFERENCES}

[1] M. Barnes and A. Beddard, "Voltage source converter HVDC links the state of the art and issues going forward," Energy Proc., vol. 24 pp. 108-122, Jan. 2012.

[2] A. Lesnicar and R. Marquardt, "An innovative modular multilevel converter topology suitable for a wide power range," in Proc., IEEE Bologna Power Tech Conf., 2003, vol. 3, pp. 1-6.

[3] D. V. Hertem and M. Ghandhari, "Multi-terminal VSC HVDC for the European supergrid: Obstacles," Renew. Sustain. Energy Rev., vol. 14, no. 9, pp. 3156-3163, Dec. 2010.
[4] R. Marquardt, "Modular multilevel converter topologies with DC-short circuit current limitation," in Proc. IEEE 8th Int. Conf. Power Electron. ECCE Asia, Jun. 2011, pp. 1425-1431.

[5] X. Li, W. Liu, Q. Song, H. Rao, and S. Xu, "An enhanced MMC topology with DC fault ride-through capability," in Proc. IEEE 39th Industrial Electron. Soc. Annu. Conf., Nov. 2013, pp. 6182-6188.

[6] M. Merlin, T. Green, P. Mitcheson, D. Trainer, D. Critchley, and R. Crookes, "A new hybrid multi-level voltage-source converter with DC fault blocking capability," in Proc. 9th IET Int. Conf. AC DC Power Transmiss., Oct. 2010, pp. 1-5.

[7] R. Feldman, M. Tomasini, E. Amankwah, J. Clare, P. Wheeler, D. Trainer, and R. Whitehouse, "A hybrid modular multilevel voltage source converter for HVDC power transmission," IEEE Trans. Ind. Appl., vol. 49, no. 4, pp. 1577-1588, Jul. 2013.

[8] M. Bucher and C. Franck, "Contribution of fault current sources in multiterminal HVDC cable networks," IEEE Trans. Power Del., vol. 28, no. 3, pp. 1796-1803, Jul. 2013.

[9] M. Bucher, R. Wiget, G. Andersson, and C. Franck, "Multiterminal HVDC networks. What is the preferred topology?,"IEEE Trans. Power Del., vol. 29, no. 1, pp. 406-413, Feb. 2014.

[10] J. Rafferty, L. Xu, and D. Morrow, "DC fault analysis of VSC based multi-terminal HVDC systems," in Proc. 10th IET Int. Conf. AC DC Power Transm., 2012, pp. 1-6.

[11] J. Yang, J. Fletcher, and J. O'Reilly, "Short-circuit and ground fault analyses and location in VSC-based DC network cables," IEEE Trans. Ind. Electron., vol. 59, no. 10, pp. 3827-3837, Oct. 2012.

[12] J. Yang, J. Fletcher, and J. OReilly, "Multiterminal DC wind farm collection grid internal fault analysis and protection design," IEEE Trans. Power Del., vol. 25, no. 4, pp. 2308-2318, Oct. 2010.

[13] H. Saad, S. Dennetiere, J. Mahseredjian, P. Delarue, X. Guillaud, J. Peralta, and S. Nguefeu, "Modular multilevel converter models for electromagnetic transients," IEEE Trans. Power Del., vol. 29, no. 3, pp. 1481-1489, Jul. 2014.

[14] W. Leterme, P. Tielens, S. De Boeck, and D. Van Hertem, "Overview of grounding and configuration options for meshed HVDC grids," IEEE Trans. Power Del., vol. 29, no. 6, pp. 2467-2475, Dec. 2014.

[15] M. Shen, L. Ingratta, and G. Roberts, "Grounding transformer application, modeling, and simulation," in Proc. IEEE Power Energy Soc. Gen. Meeting - Convers. Del. Elect. Energy 21st Century, Jul. 2008, pp. 1-8.

[16] H. Wang, G. Tang, Z. He, and J. Yang, "Efficient grounding for modular multilevel HVDC converters (MMC) on the AC side," IEEE Trans. Power Del., vol. 29, no. 3, pp. 1262-1272, Jun. 2014.

[17] R. Blasco-Gimenez, S. Añó-Villalba, J. Rodriguez-D'Derlée, S. Bernal-Perez, and F. Morant, "Diode-based HVdc link for the connection of large offshore wind farms," IEEE Trans. Energy Convers., vol. 26, no. 2, pp. 615-626, Jun. 2011.

[18] E. Belenguer, R. Vidal, H. Beltran, and R. Blasco-Gimenez, "Control strategy for islanded operation of offshore wind power plants connected through a VSC-HVDC link," in Proc. 39th IEEE Ind. Electron. Soc. Annu. Conf., Nov. 2013, pp. 5254-5259.

[19] R. Vidal-Albalate, E. Belenguer, H. Beltran, and R. Blasco-Gimenez, "Simplified model for modular multi-level converter simulation," in Proc. 11th Int. Conf. Model. Simul. Elect. Mach., Converters Syst., Valencia, Spain, May 2014, pp. 487-492.

[20] H. Dommel, "Transformer models in the simulation of electromagnetic transients," presented at the 5th Power Syst. Comput. Conf., Cambridge, U.K., Sep. 1975.

[21] J. Yang, J. O'Reilly, and J. E. Fletcher, "An overview of DC cable modelling for fault analysis of VSC-HVDC transmission systems," in Proc. Univ. Power Eng. Conf., 2010, pp. 1-5.

[22] H. Saad et al., "Dynamic averaged and simplified models for MMCbased HVDC transmission systems," IEEE Trans. Power Del., vol. 28, no. 3, pp. 1723-1730, Jul. 2013.

[23] Q. Tu, Z. Xu, and L. Xu, "Reduced switching-frequency modulation and circulating current suppression for modular multilevel converters," IEEE Trans. Power Del., vol. 26, no. 3, pp. 2009-2017, Jul. 2011.

[24] L. Angquist, A. Antonopoulos, D. Siemaszko, K. Ilves, M. Vasiladiotis, and H.-P. Nee, "Open-loop control of modular multilevel converters using estimation of stored energy," IEEE Trans. Ind. Appl., vol. 47, no. 6, pp. 2516-2524, Nov./Dec. 2011.

[25] Wind Turbines. Part 1: Design Requirements, IEC 61400-1:2005, Int. Electrotech. Comm., 2005. 
[26] S. Añó-Villalba, R. Blasco-Gimenez, S. Bernal-Perez, and E. Belenguer, "Wind power plant integration in $\mathrm{HVdc}$ grids with voltage droop control," in Proc. 11th Int. Conf. Model. Simul. Elect. Mach., Converters Syst., Valencia, Spain, 2014, pp. 573-578.

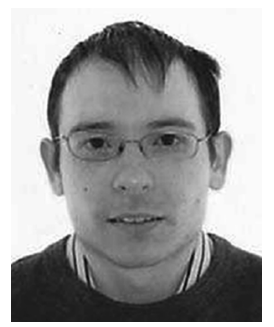

Ricardo Vidal-Albalate received the M.Sc. degree in industrial engineering from the Universitat Jaume I (UJI), Castelló de la Plana, Spain, in 2010 and is currently pursuing the Ph.D. degree in grid integration of offshore wind farms using HVDC links.

Currently, he is an Assistant Professor of the Electrical Engineering Area at UJI. He was a Visiting Scholar for six months at the Department of Electrical and Electronic Engineering of the University of Nottingham, Nottingham, U.K., in 2014.

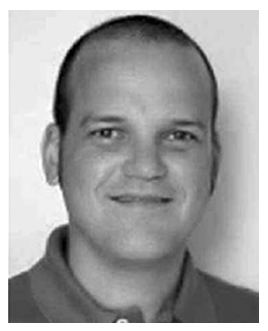

Hector Beltran received the M.Sc. degree in industrial engineering from Universitat Jaume I, Castelló de la Plana, Spain, in 2004, and the Ph.D. degree in electrical engineering from the Technical University of Catalonia (UPC), Barcelona, Spain, in 2011.

During 2003, he was with the European Organization for Nuclear Research (CERN), Geneva, Switzerland. From 2004 to 2006, he was a Researcher with the Electronic and Energy Departments, Energy Technological Institute (ITE), Valencia, Spain. Since 2006, he has been an Assistant Professor of electrical engineering with Universitat Jaume I, Castelló de la Plana, Spain. Meanwhile, he visited the Institute of Energy Technology, Aalborg University, Aalborg, Denmark (for six months), and the Renewable Electrical Energy Systems Research Group, Electrical Engineering Department, UPC (for nine months). His current research interests include massive photovoltaic integration into the grid, energy-storage systems, and microgrids.

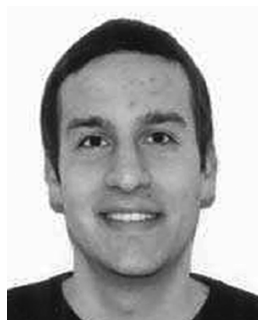

Alejandro Rolán was born in Sabadell, Spain, in 1985. He received the B.S. degree in industrial engineering and the $\mathrm{Ph} . \mathrm{D}$. degree in electrical engineering from the Technical University of Catalonia, Barcelona, Spain, in 2007 and 2012, respectively.

From 2008 to 2013, he was an Assistant Professor in the Electrical Engineering Department of the Technical University of Catalonia. Since 2013, he has been an Assistant Professor in the Department of Industrial Systems Engineering and Design Electrical Engineering Area with Jaume I University, Castelló de la Plana, Spain. His research interests lie in the areas of electric machines and power system quality, specifically with the integration of renewable energies to the main grid.

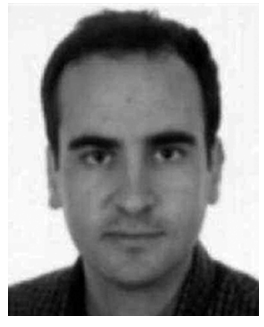

Enrique Belenguer (M'05) received the M.Sc. and $\mathrm{Ph} . \mathrm{D}$. degrees in electrical engineering from the Technical University of Valencia (UPV), Valencia, Spain, in 1992 and 1997, respectively.

Currently, he is a Professor of electrical engineering with the Universitat Jaume I, Castelló de la Plana, Spain, where he is also the Director of the BP Chair of Energy Efficiency. His research areas are power system analysis, electrical machines, power quality, and grid integration of renewable energy systems.

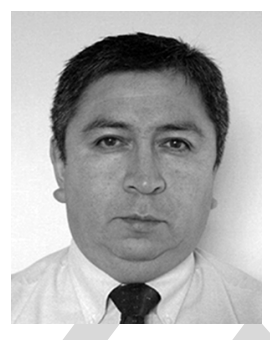

Rubén Peña (S'95-M'97) was born in Coronel, Chile. He received the M.Sc. and Ph.D. degrees [Author: in what field?] from the University of Nottingham, Nottingham, U.K., in 1992 and 1996, respectively.

From 1985 to 2008, he was a Lecturer in the Universidad de Magallanes, [Please provide city] Chile. He has been with the Electrical Engineering Department, Universidad de Concepcion, since 2008, where he is currently a Full Professor. His main interests include the control of power-electronics converters, ac drives, and renewable energy systems.

Dr. Pena received the Best Paper Award from the IEEE TRANSACTIONS ON InDUSTRIAL ElECtRONICS in 2004, and the Ramon Salas Edward Award for research excellence from the Chilean Institute of Engineers in 2009.

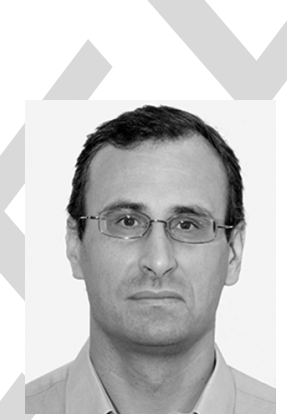

Ramon Blasco-Gimenez (S'94-M'96-SM'10) received the B.Eng. degree in electrical engineering from the Universitat Politècnica de València, València, Spain, in 1992 and the Ph.D. degree in electrical and electronic engineering from the University of Nottingham, Nottingham, U.K., in 1996.

From 1992 to 1995, he was a Research Assistant with the Department of Electrical and Electronic Engineering of the University of Nottingham. In 1996, he joined the Department of Systems Engineering and Control of the Universitat Politècnica de València, València, Spain, where he is currently an Accredited Professor. His research interests include control of HVDC systems, wind power generation, and grid integration of renewable energy systems. He has been guest co-editor of special issues of the IEEE TRANSACTIONS ON ENERGY CONVERSION and Mathematics and Computers in Simulation (MATCOM).

Dr. Blasco-Gimenez is a member of the IMACS TC1 (Electrimacs) Committee and Chair of the Renewable Energy Technical Committee of the IEEE Industrial Electronics Society. He has been a co-recipient of the 2004 IEEE TRANSACtions on Industrial Electronics Best Paper Award. He is a Chartered Engineer (U.K.) and a member of the Institute of Engineering and Technology. 